\title{
Caracterização da coleta seletiva de resíduos sólidos no Brasil: avanços e dificuldades
}

\author{
Alessandra Maria Gomes Rodrigues* \\ Eliane Pinheiro de Sousa**
}

\begin{abstract}
Resumo: O manejo de resíduos sólidos tem sido uma preocupação presente na atualidade para a administração pública e para a população brasileira em geral. Nesse contexto, o serviço de coleta seletiva tem sido apontado como alternativa inovadora para diminuir a geração de resíduos sólidos domésticos e incentivar a reciclagem. Assim, esse trabalho se propõe caracterizar a ação da coleta seletiva de resíduos sólidos no Brasil, considerando os dados de 2000 e 2008. Especificamente, pretende-se descrever os avanços dessa prática sustentável no Brasil e mostrar as dificuldades de realização dessa medida no país. Para atender a esses objetivos propostos, empregou-se uma análise tabular e descritiva, utilizando a base de dados da Pesquisa Nacional de Saneamento Básico do IBGE, nas versões de 2000 e 2008. Os dados mostraram que as regiões Sudeste e Sul obtiveram melhores resultados em termos do número de municípios que fazem uso da coleta seletiva entre 2000 e 2008. Entretanto, o desempenho dos municípios ainda está muito abaixo do necessário para reduzir a quantidade de resíduos que acabam sendo destinados inadequadamente para aterros e lixões. Portanto, conclui-se que é necessário ampliar esse serviço como uma forma de gestão dos resíduos sólidos.
\end{abstract}

Palavras-chave: Resíduos sólidos, Coleta seletiva, Brasil.

Classificação JEL: Q20, Q32, Q53.

\footnotetext{
* Graduanda em Ciências Econômicas pela Universidade Regional do Cariri (URCA) e Bolsista de Iniciação Científica PIBIC/FUNCAP.

** Doutora em Economia Aplicada pela Universidade Federal de Viçosa (UFV) e Professora adjunta do Departamento de Economia da Universidade Regional do Cariri (URCA).
} 


\section{Introdução}

De acordo com a Associação Brasileira de Resíduos Sólidos e Limpeza Pública (ABLP, 2011), ao longo dos últimos anos, o Brasil tem-se preocupado com a questão da sustentabilidade ambiental. Atualmente, a população brasileira tem aumentado a consciência quanto aos problemas do saneamento e condições de saúde. Nesse contexto, a gestão de resíduos sólidos representa um grande desafio para a sociedade brasileira, sobretudo, para a administração pública.

Esse desafio tem sido crescente em virtude da quantidade e da diversidade de resíduos produzidos; do crescimento populacional e do consumo; da ampliação de áreas urbanas; e da cultura histórica de recursos insuficientes para promover uma gestão adequada de resíduos, tendo em vista que se tem aplicado, em média, apenas $\mathrm{R} \$ 88,01$ habitante/ano com a gestão de resíduos sólidos, ocasionando uma forma indevida de destino desses resíduos em grande parte dos municípios brasileiros, ao passo que a média internacional atinge $\mathrm{R} \$$ 429,78 habitante/ano. Nesse cenário de recursos limitados, torna-se desafiador obter a qualidade e a inovação tecnológica almejadas aos serviços de limpeza urbana, sobretudo, quando se pretende alcançar um horizonte de longo prazo (ABLP, 2011).

O manejo de resíduos sólidos abrange ações desempenhadas durante as fases de coleta, limpeza pública e destinação final desses resíduos. No tocante à coleta dos resíduos sólidos, vale destacar que um dos processos utilizados é a coleta seletiva, que se refere à separação e classificação do lixo entre os materiais, podendo ser reaproveitados ou reciclados da parte inadequada para essas finalidades. Esse processo possibilita a diminuição da quantidade de resíduos que são destinados para locais não apropriados, assim como incentiva a reciclagem.

Segundo o Instituto Brasileiro de Geografia e Estatística (IBGE, 2010), a partir de meados da década de 1980, tem-se início no Brasil os programas pioneiros de coleta seletiva e reciclagem, que passaram a atuar como formas alternativas inovadoras para diminuir a geração de resíduos sólidos domésticos e incentivar a reciclagem. Essas ações representaram um avanço no sentido de empresas, indústrias, comunidades organizadas e gestores locais melhorarem suas práticas de manejo de resíduos sólidos.

Os primeiros dados oficiais levantados sobre a coleta seletiva de resíduos sólidos no Brasil foram divulgados pela Pesquisa Nacional de Saneamento Básico (PNSB) 1989, que sinalizou a presença de 58 programas em todo o País, passando para 451, conforme a PNSB 2000, e para 994 na PNSB 2008. Esse crescimento mostra o avanço da adoção dessa prática nos municípios brasileiros (IBGE, 2010).

No entanto, quando se compara o número de municípios que utiliza a coleta seletiva com o número total de municípios, percebe-se que ainda há um longo caminho a ser percorrido para se conseguir avanços mais significativos.

Assim, verifica-se que, mesmo o Brasil possuindo uma legislação avançada, concernente à Política Nacional de Resíduos Sólidos (PNRS), que 
prevê, dentre outras ações, a obrigatoriedade da coleta seletiva, o país convive com o atraso na aplicação dessa lei. A população tem interesse de participar desse serviço, porém não é atendida pelos gestores em parcela majoritária dos municípios brasileiros, que alegam a falta de orçamento para investir na coleta seletiva. Entretanto, existem recursos disponíveis, mas seu acesso se depara com as dificuldades de ausência de planejamento e projetos (Brito, 2013).

Para Brito (2013), a falta da coleta seletiva de resíduos sólidos, além de ser um problema ambiental, representa um grande desperdício de recursos, pois, conforme dados fornecidos pelo Ministério do Meio Ambiente, o valor dos resíduos recicláveis que são destinados aos lixões pela ausência desse serviço pode atingir $\mathrm{R} \$ 8$ bilhões ao ano. Ademais, esse valor ainda pode ser acrescido dos custos para coletar, transportar e dispor esse material.

Em face dessas considerações, verifica-se a importância de tratar essa questão no Brasil. A coleta seletiva foi abordada nos trabalhos desenvolvidos mais recentemente por Pes et al. (2011); Gomes e Steibrück (2011); Jacobi e Besen (2011); e Vieira e Garcia (2012). O primeiro realizou um estudo de caso no município de Primavera do Leste, localizada no sudeste de Mato Grosso, em que se buscou mostrar os benefícios desse programa por meio do uso de dados primários coletados em uma pesquisa de campo.

Os três últimos apontaram a coleta seletiva como um sistema de gestão sustentável dos resíduos sólidos. Gomes e Steibrück (2011) trataram essa questão sob o enfoque da legislação vigente da Política Nacional de Resíduos Sólidos. Jacobi e Besen (2011) abordaram essa temática em São Paulo, destacando o importante papel da coleta seletiva com inclusão de catadores de materiais recicláveis na cidade de São Paulo como estratégia para promover a sustentabilidade socioambiental urbana. Por sua vez, Vieira e Garcia (2012) investigaram a gestão de resíduos sólidos domésticos no Brasil e compararam a situação brasileira com o cenário internacional. Entretanto, nenhum desses estudos mostrou a evolução desse sistema de gestão nas regiões brasileiras, indicando seus avanços e dificuldades, constituindo na inovação deste trabalho.

Nesse sentido, esse trabalho tem como objetivo principal caracterizar a ação da coleta seletiva de resíduos sólidos no Brasil, considerando os dados de 2000 e 2008. Especificamente, pretende-se descrever os avanços dessa prática sustentável no Brasil e mostrar as dificuldades de realização dessa medida no país.

\section{Metodologia}

O estudo empregou uma análise tabular e descritiva, com o intuito de comparar as características da coleta seletiva adotada no Brasil em 2000 e em 2008, destacando seus principais avanços e dificuldades. Para isso, utilizou-se uma base de dados de natureza secundária, fornecida pelo Instituto Brasileiro de Geografia e Estatística através da Pesquisa Nacional de Saneamento Básico nas versões de 2000 e 2008, contidas, respectivamente, nas publicações do IBGE 
(2002) e IBGE (2010), sendo que, no presente estudo, foram utilizados apenas os dados referentes à coleta seletiva com informações comuns nos dois anos considerados que permitissem a análise comparativa.

\section{Resultados e Discussão}

A tabela 1 mostra as estatísticas descritivas da coleta seletiva no Brasil e nas cinco regiões brasileiras em 2000 e 2008. Como se verifica, tanto em 2000 quanto em 2008, existem estados da região Norte que não possuem coleta seletiva em nenhum dos seus municípios. Em 2000, o único estado do Norte que registrou a prática da coleta seletiva foi Rondônia com um único município utilizando esse serviço, enquanto, em 2008, esse município de Rondônia deixou de utilizar a coleta seletiva e o estado do Amapá continuou sem adotar esse serviço em seus municípios. O estado que teve o maior número de municípios seguindo essa medida foi o Pará com 11 municípios.

Dos nove estados que fazem parte do Nordeste brasileiro, três deles (Maranhão, Piauí e Sergipe) não fizeram uso da coleta seletiva em seus municípios em 2000, sendo que o estado com o maior número de municípios utilizando essa prática foi a Bahia com 12 municípios em 2000. Esse estado também liderou o número máximo de municípios que adotam esse serviço em 2008, passando para 28 municípios. Todos os estados nordestinos registraram acréscimos de municípios com adoção desse tipo de serviço entre 2000 e 2008, sendo que os mais expressivos foram o Maranhão, que passou de 0 para 5 municípios; Alagoas, que passou de 1 para 5 municípios; e Rio Grande do Norte, que passou de 2 para 10 municípios.

Tabela 1 - Estatísticas descritivas da coleta seletiva por região brasileira, 2000 e 2008.

\begin{tabular}{lcccccccccccc}
\hline & \multicolumn{2}{c}{ Norte } & \multicolumn{2}{c}{ Nordeste } & \multicolumn{2}{c}{ Sudeste } & \multicolumn{2}{c}{ Sul } & \multicolumn{2}{c}{ Centro-Oeste } & \multicolumn{2}{c}{ Brasil } \\
\cline { 2 - 13 } & 2000 & 2008 & 2000 & 2008 & 2000 & 2008 & 2000 & 2008 & 2000 & 2008 & 2000 & 2008 \\
\cline { 2 - 13 } Mínimo & 0 & 0 & 0 & 2 & 7 & 8 & 63 & 98 & 1 & 1 & 0 & 0 \\
Média & 0,1 & 3 & 3 & 8,9 & 35 & 102 & 91,3 & 151,3 & 2,2 & 7,75 & 16,7 & 36,8 \\
Máximo & 1 & 11 & 12 & 28 & 82 & 223 & 138 & 190 & 5 & 15 & 138 & 223 \\
DV* & 0,4 & 4,1 & 4,4 & 8,5 & 35,7 & 105,9 & 91,3 & 40,7 & 1,9 & 5,8 & 33,6 & 65,8 \\
$C V^{* * *}(\%)$ & 264,6 & 136,1 & 146,2 & 95,5 & 102 & 103,9 & 44,6 & 31,5 & 84,1 & 75,5 & 201,4 & 178,9 \\
\hline
\end{tabular}

Fonte: Elaborado pelos autores com base nos dados do IBGE (2002 e 2010).

Nota: * DV representa desvio padrão e ** CV representa coeficiente de variação.

No Centro Oeste, o estado do Mato Grosso do Sul foi responsável pelo maior número de municípios com uso da coleta seletiva em 2000 com 5 municípios, ao passo que Goiás foi o estado que obteve o maior número de municípios que adotaram esse serviço em 2008, totalizando 15 municípios. Esse estado também apresentou o maior crescimento de municípios que passaram a implementar essa medida, passando de 2 para 15 municípios entre 2000 e 2008. No Distrito 
Federal, somente um município registrou essa prática tanto em 2000 quanto em 2008.

As regiões Sudeste e Sul foram as que obtiveram melhores resultados em termos do número de municípios que fazem uso da coleta seletiva como uma forma de gestão dos resíduos sólidos. No Sudeste, os estados com maior e menor número de municípios que adotam esse tipo de gestão foram, respectivamente, São Paulo, que passou de 82 para 223 municípios e Espírito Santo, que passou de 7 para 8 municípios entre 2000 e 2008. Entretanto, foi o estado de Minas Gerais que registrou o maior aumento de municípios que passou a incorporar esse serviço, passando de 37 municípios em 2000 para 155 municípios em 2008.

O Sul brasileiro apesar de ter apresentado o maior número de municípios com uso da coleta seletiva em 2000 com 138 municípios, não liderou o ranking em 2008, ficando o Sudeste como melhor colocado. Esse serviço foi utilizado por 223 municípios de São Paulo, enquanto o maior número de municípios sulistas foi o estado do Paraná com 190 municípios, que também representou o estado com a maior expansão de municípios que adotaram a coleta seletiva, passando de 73 municípios em 2000 para 190 municípios.

Em termos médios, o Brasil, assim como todas as regiões brasileiras, teve acréscimo de municípios que fizeram uso da coleta seletiva entre 2000 e 2008, sendo que apesar da região Norte ter registrado os menores valores absolutos de municípios que utilizavam esse serviço, foi essa região que teve o maior aumento relativo, passando de uma média de 0,1 para 3 municípios entre 2000 e 2008.

No tocante ao coeficiente de variação, de 2000 para 2008, ocorreu uma redução do seu valor de 201,4 \% para 178,9 \%, no contexto nacional. Essa redução da variabilidade foi observada em todas as regiões brasileiras, com exceção do Sudeste, que registrou um ligeiro aumento no coeficiente de variação nesse período, sendo que a menor dispersão foi verificada na região Sul, enquanto o Norte brasileiro apresentou maior heterogeneidade em seus municípios quanto à coleta seletiva.

A partir dos dados da tabela 2, constata-se um aumento no número de municípios que adotam o serviço de coleta seletiva em 2008 em relação a 2000 , passando de 451, que corresponde a 8,19\% em 2000 para 994, que representa $17,86 \%$ em 2008. Verifica-se que o maior aumento ocorreu na região Sudeste, que passou de 8,40\% dos municípios em 2000 para 24,46\% em 2008, registrando um acréscimo de 16,06\% dos municípios; e o menor na região Nordeste, que passou de 1,51\% em 2000 para 4,46\% em 2008, que perfez uma expansão de $2,95 \%$ dos municípios nordestinos. A região Sul apresentou a maior abrangência de municípios que utilizam esse tipo de serviço tanto em 2000 quanto em 2008.

Porém, segundo Gomes e Steinbrück (2011), o desempenho dos municípios ainda se encontra muito abaixo dos patamares indispensáveis para efetivamente diminuir a quantidade de resíduos potencialmente recicláveis, que são colocados em aterros ou lixões. Essa concepção é corroborada por Bizzotto et al. (2010) apud Jacobi e Besen (2011) que destacam que em São Paulo apenas cerca de $1 \%$ do total coletado diariamente na cidade é desviado do aterro pelo 
programa oficial de coleta seletiva.

Tabela 2 - Participações absolutas e relativas das regiões brasileiras que adotam o serviço de coleta seletiva, 2000 e 2008

\begin{tabular}{lcccccc}
\hline Regiões & $\begin{array}{c}\text { Total de } \\
\text { municípios } \\
\text { em 2000 }\end{array}$ & $\begin{array}{c}\text { Coleta seletiva em } \\
\text { atividade em 2000 }\end{array}$ & $\begin{array}{c}\text { Total de } \\
\text { municípios } \\
\text { em 2008 }\end{array}$ & $\begin{array}{c}\text { Coleta seletiva em } \\
\text { atividade em 2008 }\end{array}$ \\
\cline { 3 - 4 } Norte & 449 & 1 & 0,22 & 449 & 21 & 4,68 \\
Nordeste & 1787 & 27 & 1,51 & 1793 & 80 & 4,46 \\
Sudeste & 1666 & 140 & 8,40 & 1668 & 408 & 24,46 \\
Sul & 1159 & 274 & 23,64 & 1188 & 454 & 38,22 \\
Centro-oeste & 446 & 9 & 2,02 & 466 & 31 & 6,65 \\
\hline BRASIL & 5.507 & 451 & 8,19 & 5.564 & 994 & 17,86 \\
\hline
\end{tabular}

Fonte: Elaborado pelos autores com base nos dados do IBGE (2002 e 2010).

Com base nos dados da tabela 3, observa-se que embora tenha ocorrido um aumento do número de municípios que utiliza o serviço de coleta seletiva em todo o município de 178 em 2000 para 377 em 2008, os municípios apresentam dificuldades em realizar a coleta abrangendo todo o município, uma vez que o percentual do número de municípios que adota a coleta seletiva em todo o município diminuiu, passando de 39,47\% em 2000 para 36,60\% em 2008, no Brasil. Em termos regionais, verifica-se que no Centro-Oeste e no Sudeste ocorreram uma redução na variação percentual, respectivamente, de $28,82 \%$ e $6,43 \%$ entre 2000 e 2008. Já nas regiões Nordeste, Norte e Sul, ocorreram um aumento percentual, sendo a região Nordeste a que teve uma variação mais expressiva, passando de 18,52\% em 2000 para 33,71\% em 2008.

No que diz respeito à abrangência da coleta seletiva em toda a área urbana da Sede municipal, os dados indicam que em todas as grandes regiões brasileiras, com exceção da região Nordeste, ocorreu um aumento na variação percentual de municípios entre 2000 e 2008. Esse resultado pode estar associado ao deslocamento territorial, dentro do próprio município.

Em relação aos bairros selecionados, houve uma redução na variação percentual, em todas as áreas, dos que apresentam coleta seletiva. Dentre as regiões brasileiras, constata-se que o Norte e o Centro-Oeste apresentaram, respectivamente, maior e menor variação, pois a primeira passou de $100 \% \mathrm{em}$ 2000 para $22,73 \%$ em 2008 , e a segunda passou de $22,22 \%$ em 2000 para $21,88 \%$ em 2008. 
Tabela 3 - Municípios com serviço de coleta seletiva, por área de abrangência, 2000 e 2008**

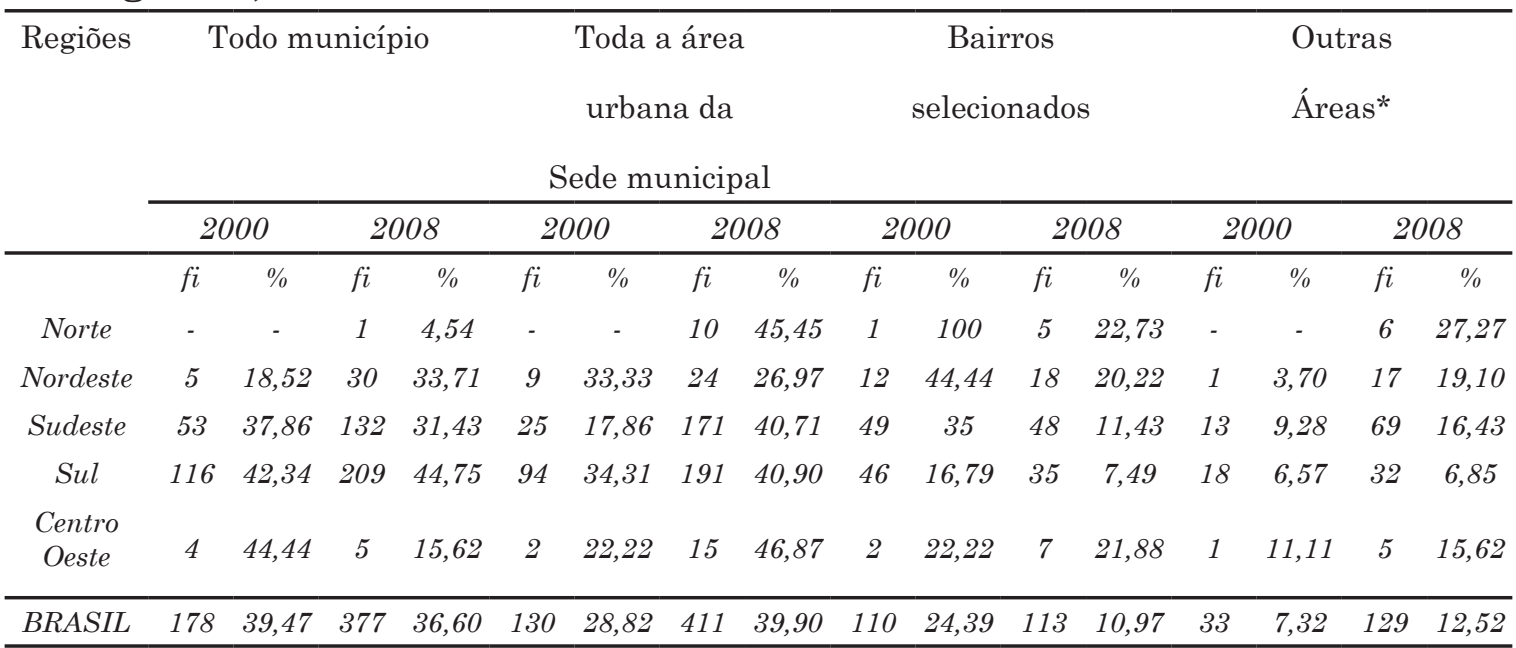

Fonte: Elaborado pelos autores com base nos dados do IBGE (2002 e 2010).

Notas: * Essa categoria outros inclui outras áreas e aquelas sem declaração, em 2000. Já em 2008, essa categoria inclui exclusivamente alguns bairros da área urbana da sede municipal e outros.

** Segundo a PNSB (2008), no município pode existir mais de uma área de abrangência de coleta seletiva. Sendo assim, o total na tabela de coleta seletiva, em 2008, está considerando a soma de todas as áreas de abrangência, e não a quantidade de municípios que possuem coleta seletiva por área de abrangência.

\section{Conclusões}

Mesmo com um cenário marcado pela escassez de recursos para destinarem-se a coleta seletiva, a preocupação com a redução dos impactos negativos ao meio ambiente e o aumento da conscientização da população brasileira em relação aos problemas de saneamento e saúde deixam evidente a necessidade de uma política que proporcione a adequada gestão dos resíduos sólidos.

A implementação da coleta seletiva traz benefícios para os municípios como o aproveitamento de recursos por meio da reciclagem, que antes seriam desperdiçados, a minimização dos impactos ambientais negativos, a participação da comunidade no sentido de melhorar as práticas de manejo de resíduos sólidos. Tendo em vista essas vantagens, a população manifesta interesse em participar desse serviço, tornando-se necessária a atuação dos gestores públicos. Assim, esses gestores precisam colocar em prática a coleta seletiva em seus municípios, ou, no caso daqueles em que já existem, dar continuidade, e ampliar a área de abrangência e o número de pessoas e entidades envolvidas.

Conforme os resultados apresentados nesse trabalho, já ocorreram avanços significativos quanto ao manejo de resíduos sólidos, sendo mais expressivo nas regiões Sudeste e Sul, porém o desempenho dos municípios ainda está muito abaixo do necessário para reduzir a quantidade de resíduos que acabam sendo destinados inadequadamente para aterros e lixões. Entretanto, 
para que seja possível superar esses desafios, os gestores têm que planejarem adequadamente como isto deverá ocorrer, e, a partir de então, alocarem os recursos disponíveis para esse fim.

\section{Referências}

Associação Brasileira de Resíduos Sólidos e Limpeza Pública (ABLP) (2013). Guia de orientação para adequação dos municípios à Política Nacional de Resíduos Sólidos (PNRS). São Paulo: ABLP, 2011, 135p. Disponível em: <http:www.ablp. org.br>. Acesso em: 13 de abril 2013.

Brito, M. C. W. (2013). "Brasileiros querem coleta seletiva." In: Envolverde Jornalismo \& Sustentabilidade. Disponível em: http://envolverde.com.br/ambiente/ brasileiros-querem-coleta-seletiva. Acesso em: 13 de abril 2013.

Gomes, E. R.; Steinbrück, M. S. A. (2011). As oportunidades e os dilemas do tratamento dos resíduos sólidos à luz da lei n ${ }^{\circ} .12 .305$ - Política Nacional de Resíduos Sólidos. In: Encontro da Sociedade Brasileira de Economia Ecológica, 9, 2011. Anais... Brasília, DF: ECOECO.

Instituto Brasileiro de Geografia e Estatística (IBGE) (2000). Pesquisa Nacional de Saneamento Básico - PNSB. Rio de Janeiro: IBGE, 2002, 397 p.

Instituto Brasileiro de Geografia e Estatística (IBGE) (2010). Pesquisa Nacional de Saneamento Básico - PNSB 2008. Rio de Janeiro: IBGE, 2010, 219 p.

Jacobi, P. R.; Besen, G. R. (2011). "Gestão de resíduos sólidos em São Paulo: desafios da sustentabilidade.” Estudos Avançados. São Paulo, v. 25, n. 71, 2011.

Pes, D. A.; Grasel, D.; Nicásio, J. E. M.; Henig, (2011). E. V. "Gestão de resíduos sólidos: o caso da coleta seletiva em Primavera do Leste / MT." In: Encontro da Sociedade Brasileira de Economia Ecológica, 9. Anais... Brasília, DF: ECOECO, 2011.

Vieira, A. C. P.; Garcia, J. R. (2012). "A gestão de resíduos sólidos domésticos no Brasil a par da experiência internacional.” Revista Economia \& Tecnologia (RET), v. 8, n. 4, p. 57-66. 